\title{
Investigating small unoccupied aerial systems (sUAS) multispectral imagery for total suspended solids and turbidity monitoring in small streams
}

\author{
Elizabeth M. Prior (iD ${ }^{a, b}$, Frances C. O’Donnella , Christian Brodbeck ${ }^{c}$, G. Brett Runion ${ }^{d}$ \\ and Stephanie L. Shepherd ${ }^{\mathrm{e}}$
}

aBiological Systems Engineering Department, Virginia Tech, 155 Ag Quad Lane, Blacksburg, VA 24060, USA; ${ }^{b}$ Department of Biological Systems Engineering, Virginia Tech, Virginia, VA, USA; 'Department of Biosystems Engineering, Auburn University, Auburn, AL, USA; 'National Soil Dynamics Laboratory, ARS-USDA, Auburn, AL, USA; 'Department of Geosciences, Auburn University, Auburn, AL, USA

\begin{abstract}
Small unoccupied aerial systems (sUAS) are increasingly used for field data collection and remote sensing purposes. Their ease of use, ability to carry sensors, low cost, precise manoeuvrability and navigation makes them versatile tools. The goal of this study is to investigate if sUAS multispectral imagery can be utilized to measure turbidity and total suspended solids (TSS) of small streams. sUAS multispectral imagery and water samples at varying depths were collected before and after rain events on three sampling dates in 2019 from Moores Creek in Lanett, Alabama (AL), United States of America (USA), which was restored in 2017. The water samples were processed for TSS and turbidity and related to pixel values from the multispectral imagery. Linear regression was used to develop models for TSS and turbidity. The models were then tested on Moores Mill Creek in Chewacla State Park, AL, USA.

For Lanett, TSS and turbidity regression models for low flows had coefficients of determination $\left(R^{2}\right)$ values of 0.77 and 0.78 , respectively. During high flows, different single bands and band ratios were required for comparable $R^{2}$ values, suggesting separate models may be needed for high and low flow events. When the Lanett models were applied to Chewacla State Park, predicted TSS and turbidity were not comparable to measured values indicating that location-specific models may be required. Future research should incorporate depth as a variable since streambed visibility likely impacts results, along with other modelling and data analysis methods, such as machine learning.
\end{abstract}

\section{ARTICLE HISTORY}

Received 19 December 2019

Accepted 24 May 2020

\section{Introduction}

Nonpoint source water pollution is a global issue with sedimentation and siltation at its core (Duda 1993; Bailey and Waddell 1979; Rabení and Jacobson 1999). Sedimentation/ siltation is when solids enter a waterway, increasing turbidity and total suspended solids (TSS) concentration. This can occur as runoff from agriculture, roadways, construction 
sites, logging and mining (Brown and Froemke 2012; Cooper 1993; Perez et al. 2014). These activities disturb land cover and loosen soil which can be transported in runoff (Poesen et al. 1996). Sediment, especially from agriculture, can transfer excess nutrients into waterways, causing algal blooms, which will decrease dissolved oxygen levels thus causing aquatic organisms to die while increasing turbidity and TSS levels (Michalak et al. 2013; Beman, Arrigo, and Matson 2005). Suspended particles transport many other bound contaminants, such as pathogens, hydrophobic organic contaminants and heavy metals (Chuan and Yunus 2019; Léopold et al. 2008; Rügner et al. 2014; Abia et al. 2017; Burton, Gunnison, and Lanza 1987). Additionally, suspension and deposition of sediment in waterways can negatively impact aquatic organisms and lead to alterations in food webs (Rabení, Doisy, and Zweig 2005; Minshall 1988; Rabení and Minshall 1977; Wohl et al. 2015). Soil erosion and sedimentation have been accelerated by anthropogenic disturbance (Pimentel and Kounang 1998). For just the United States, siltation, sedimentation and turbidity are the largest impairment cause, accounting for $31 \%$ of impaired waterways, while the second largest cause, pathogens, only accounts for $10 \%$ of impaired waterways (USEPA 2015). Acceleration of sedimentation/siltation can reasonably be expected to continue with projected increases in urbanization, land development, human population and global climate change (Walker, McNutt, and Maslanka 1999).

New technologies are being implemented to address increased TSS and turbidity, including green infrastructure for stormwater management, stream restoration, erosion/ sediment control devices, and conservation-based agricultural practices (Perez et al. 2016; Keeley et al. 2013; Torbert, Potter, and Morrison 1996; Potter, Torbert, and Morrison 1995; McDowell and McGregor 1984). Many sedimentation/siltation reduction measures target small streams because watersheds have most of their stream length in lower-order streams (Leopold, Wolman, and Miller 2012). This means that lower-order stream health will have the largest impact on the watershed since the watershed mostly consists of them and their small size allows human impact to dominate (Meyer et al. 2003; Sweeney et al. 2004). Excess sedimentation/siltation in small, lower-order streams needs to be addressed because of their prevalence, increased biodiversity and influential role in nutrient processing (Kaplan et al. 2008).

Measures to reduce sedimentation/siltation in small streams need to be monitored and assessed to ensure that these practices are effective in reducing TSS and turbidity. Historically, there has been a lack of stream monitoring, especially for stream restoration (Friberg et al. 2016; Bash and Ryan 2002). Long-term monitoring will allow for refined assessment of pollution prevention while also identifying areas with critical need. Traditional monitoring involves taking water samples at discrete points. This technique is labour- and time- intensive particularly if high spatial and temporal resolutions are desired.

There are multiple remote sensing methods for monitoring water quality in stream and river corridors that could address this gap (Tomsett and Leyland 2019). Several studies have used acoustic doppler and echo sounding techniques for measuring TSS in the laboratory and field setting (Schindler and Robert 2004; Chanson et al. 2011; Leyland et al. 2017). These methods are not widely used, require expensive equipment and can only be used at a reach scale (Tomsett and Leyland 2019). Remotely sensed satellite imagery has also been used to estimate surface turbidity and TSS concentrations with various resolutions ranging from $30 \mathrm{~m}$ to $1000 \mathrm{~m}$ using either Landsat or Moderate Resolution Imaging 
Spectroradiometer (MODIS) (Umar, Rhoads, and Greenberg 2018; Tomsett and Leyland 2019). These methods require long-term in situ discharge and water quality measurements and are limited to large bodies of water due to the coarse spatial resolution (Manfreda et al. 2018; Larson et al. 2018; Klemas 2015; Lechner et al. 2012; Becker et al. 2019). Additionally, these methods have difficulty in examining downstream confluence mixing and assessing multithread waterway systems (Umar, Rhoads, and Greenberg 2018). A variety of data analysis methods have been used from simply implementing linear and non-linear regression, to more recent studies addressing the complexity of surface water quality parameters using machine learning and neural networks (Sharaf El Din, Zhang, and Suliman 2017; Brando and Dekker 2003). From review of previous studies, there is an evident absence of lower-order stream remote sensing because of the lack of resolution needed to only have pixels of a stream (Liu, Islam, and Gao 2003). Also, water quality satellite remote sensing studies have mostly focused on deep uniform waters, where bottom effect and bathymetry do not have to be considered and thus surface water quality is the focus. There have been a number of satellite remote sensing water quality studies of shallow lakes (Tyler et al. 2006; Dekker et al. 1996; Hicks et al. 2013; Mironga 2004), but these field sites do not experience dynamic changes in flow rates from rain events and act as more of a sediment sink than a sediment transport mechanism. Due to the lack of resolution and focus on large sediment sinks, such as oceans and lakes, more studies need to be conducted on lower-order streams. A potential avenue to address these limitations is to use small unoccupied aerial systems (sUAS).

sUAS are increasingly used for environmental data collection due to their commercial availability, ease of use and ability to collect data at high spatial and temporal resolutions (Manfreda et al. 2018; Nowak, Dziób, and Bogawski 2019; Simic; Milas et al. 2018). There has been an increase in use of sUAS by industry, academia, government agencies and stakeholders (McDonald 2019), whereas satellite remote sensing has been almost solely used in academia and by federal agencies (Schaeffer et al. 2013). Studies of sUAS remote sensing for water quality purposes, especially in small streams are limited. Plume contaminant and inflow sUAS detection has been done with thermal imaging, which relies on the temperature difference between the effluent and the water body. This has been done in several studies in streams, rivers and coastal areas (Lega et al. 2012; Lega and Napoli 2010; Fitch et al. 2018; Briggs et al. 2018). Multispectral sUAS remote sensing of turbidity in small reservoirs suffered from model overfitting and large errors (Su 2017). A similar sUAS study was conducted on a small lake, but with coarser resolution of $0.2 \mathrm{~m}$ (Vogt and Vogt 2016). Recently, a turbidity sUAS multispectral study on a stream was conducted, with a range of turbidity measurements due to a natural spring and humaninduced sediment plume (Ehmann, Kelleher, and Condon 2019). This study only looked at individual bands or individual band ratios, did not incorporate depth-integrated sampling and did not maintain exact sampling locations. Additionally, sUAS multispectral imagery has been used to develop multi-depth models for predicting TSS in rivers with some success (Larson et al. 2018), but the technique has not been extended to small streams.

The main problem this research addresses is that small streams require turbidity and TSS monitoring, but are too small to be monitored with satellite remote sensing. The goal of this study is to develop and test statistical models to determine TSS and turbidity levels of small streams through multispectral imagery obtained by a sUAS. This study 
follows a sampling method that attempts to address the need for vertical distribution of sediment concentrations in shallow moving waters due to the influence of variable bathymetry, streambed reflectance and bed load reflectance contribution (Liu, Islam, and Gao 2003; Larson et al. 2018). Multispectral imagery and water samples at varying depths were collected before and after rain events from a recently restored reach of Moores Creek in Lanett, Alabama (AL), United States of America (USA). The water samples were analysed for TSS and turbidity and linked to pixel values from the multispectral imagery. Multiple linear regression was used to develop models relating multispectral pixel values to TSS and turbidity. To determine if models developed with the Lanett datasets can be used on similar streams, a sUAS flight and water samples were collected at Moores Mill Creek in Chewacla State Park, AL, USA. The pixel values from Chewacla were inputted into the Lanett models and results were compared to measurements. While linear regression modelling is the simplest option for data analysis, it is the necessary first step in studying sUAS remote sensing of lower-order streams, since such little research has been conducted on these locations thus far. With further refinement, sUAS high resolution multispectral imagery has the potential to improve understanding of complex fluvial geomorphological processes such as sediment transport due to variation in flows and depths. Also, sUAS could be used to identify sediment sources and be used as a monitoring tool for sedimentation/siltation reduction projects.

\section{Methods}

\subsection{Study sites}

\subsubsection{Moores Creek, Lanett, AL, USA}

Data collection for regression model development was conducted on a $244 \mathrm{~m}$ reach of Moores Creek in Lanett, AL, USA $\left(32^{\circ} 51^{\prime},-85^{\circ} 11^{\prime}\right)$ including the confluence with Jennings Creek, a small tributary (Figure $3(b, d)$ ). The reach and tributary were restored by the $A L$ Cooperative Extension System in May 2017. The restoration included a riffle, two cross vanes, one J hook, a stone wall, and live stakes for vegetation growth and stream bank stabilization (Figure 1) (ADEM 2018). The Moores Creek watershed consists of $26.2 \mathrm{~km}^{2}$ (Ries et al. 2017) with 4\% impervious surfaces and 20\% urban development (Homer, Fry, and Barnes 2012). The Moores Creek watershed is located in the Middle ChattahoocheeLake Harding River Basin (HUC 03130002) (Steeves and Nebert 1994). Moores Creek has been listed on Alabama's Clean Water Act section 303(d) use impairment list since 2012 for siltation and since 2018 for E. coli. Moores Creek was placed on this list for siltation exceeding 50 nephelometric turbidity units (NTU) above background, with background defined as the natural turbidity of receiving waters without anthropogenic effects. Additionally, Moores Creek was placed on the list for pathogens since it exceeded a geometric mean of 548 colonies per $100 \mathrm{ml}$ (ADEM 2019).

\subsubsection{Chewacla State Park, Moores Mill Creek, AL, USA}

Data collection for cross-site regression model testing was conducted in Chewacla State Park near Auburn, AL, USA on Moores Mill Creek, $\left(32^{\circ} 33^{\prime},-85^{\circ} 28^{\prime}\right)$ (Figure 3(a,c)). Water sampling occurred upstream of Chewacla Lake on $414 \mathrm{~m}$ of Moores Mill Creek. The Moores Mill Creek watershed consists of $30.1 \mathrm{~km}^{2}$ (Ries et al. 2017) with 17\% impervious 
(a)

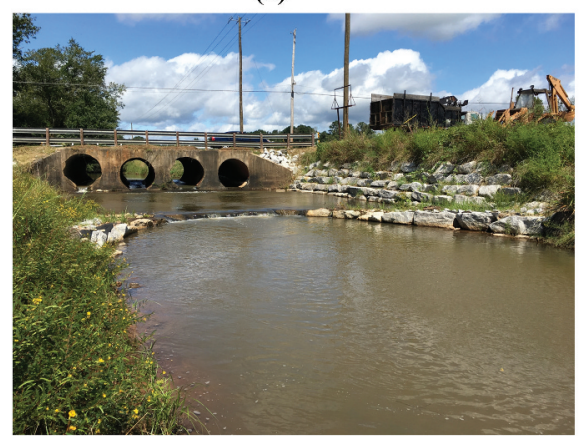

(c)

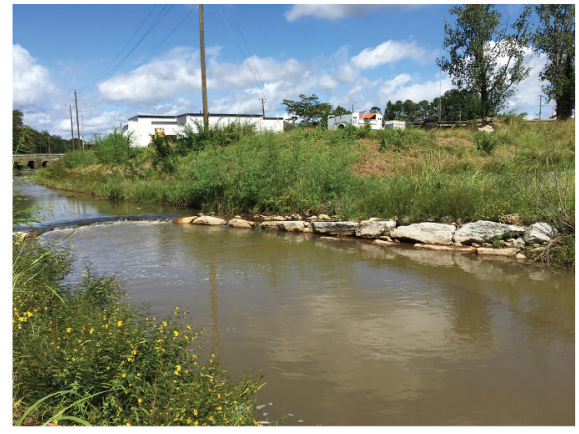

(b)

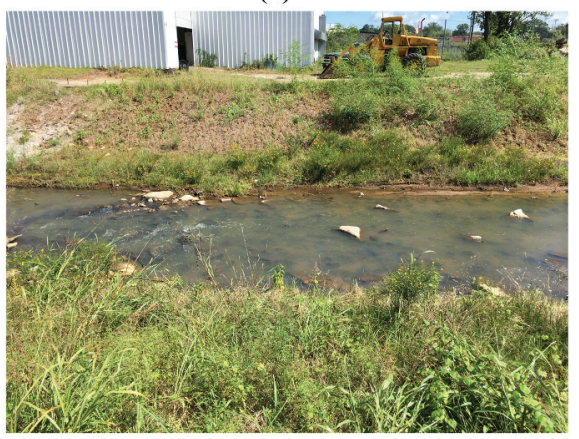

(d)

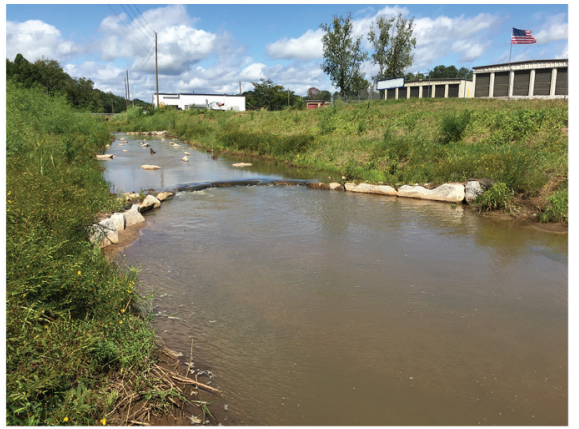

Figure 1. In-stream structures at Moores Creek, Lanett, AL, USA stream restoration site: (a) upstream cross vane with stone wall, $(b)$ riffle, $(c)$ J hook with inflow from Jennings Creek, $(d)$ downstream cross vane.

surfaces and 63\% urban development (Homer, Fry, and Barnes 2012). The Moores Mill Creek watershed is located in the Lower Tallapoosa River Basin (HUC 03150110) (Steeves and Nebert 1994). Moores Mill Creek has been on Alabama's Clean Water Act section 303 (d) use impairment list for siltation since 2000. Moores Mill Creek was placed on this list for exceeding 50 NTU above background, with background defined as the natural turbidity of receiving waters without anthropogenic effects (ADEM 2019). For the rest of this paper, datasets collected from Moores Mill Creek with be referred to as Chewacla, while datasets collected from Moores Creek will be referred to as Lanett.

\section{3. sUAS setup}

For this study, the sUAS platform (Table 1) consisted of a DJI Phantom 4 (DJ Ltd., Shenzhen, China) with a mounted Parrot Sequoia (Parrot Drone, Paris, France) multispectral sensor package. The sensor package consisted of a solar radiation sensor for auto calibration along with four band sensors capable of only receiving green $(G)$, red $(R)$, red edge (RE) and near-infrared (NIR) spectral bands. One-point calibration plus the solar radiation sensor was used for radiometric calibration using a test pattern with known reflectance (Poncet et al. 2019). 
(a)

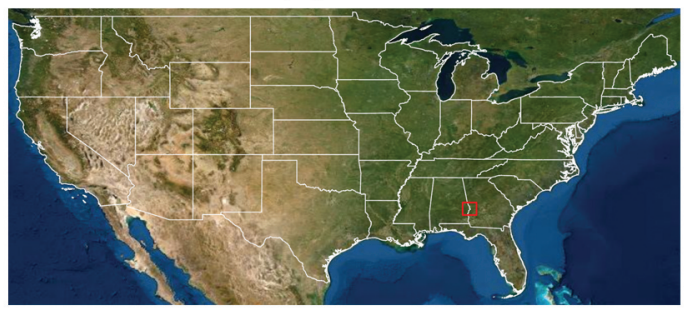

(b)

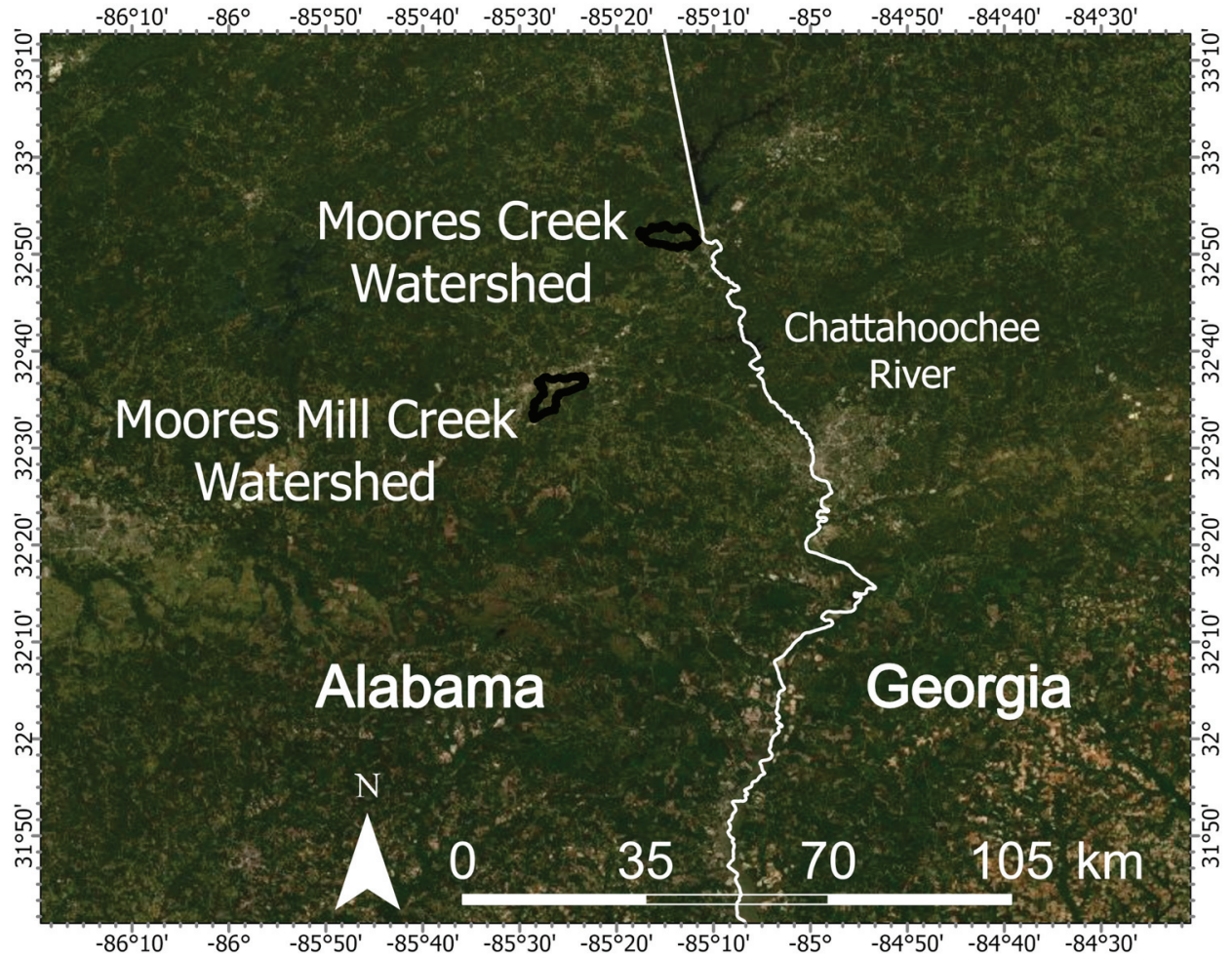

Figure 2. Geographic location of the two east AL watersheds used in this study: (a) reference map with state outlines, $(b)$ zoom in to the Alabama Georgia border where the watershed study sites are located.

\subsection{Data collection}

Data collection at Lanett included three sets of water samples and multispectral imagery on 1 February 2019, 22 March 2019 and 10 July 2019. No previous rain events were closely recorded, within the typical hydrograph response time of the reach, when the 1 February 2019 and 22 March 2019 sample sets were collected. Rain had not been recorded since 30 January 2019 and 15 March 2019, respectively. The 10 July 2019 sample set was collected 8 hours after a rain event $(1.58 \mathrm{~h}, 4.19 \mathrm{~cm})$.

Water samples were taken upstream and downstream of in-stream structures at the same locations on each sampling date (Figure 3(d)). These locations were preserved between each sample set by firmly placing metal posts on the stream banks for in-stream 
(a)

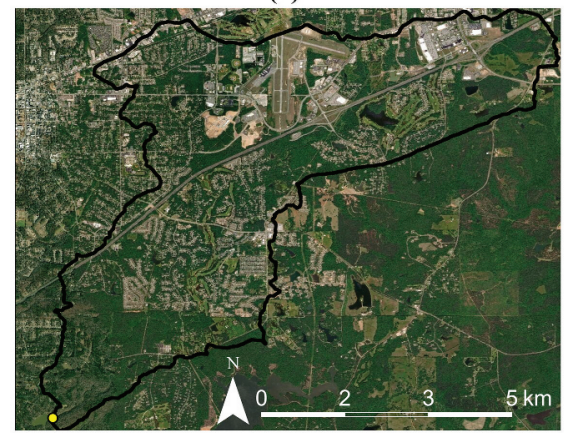

(c)

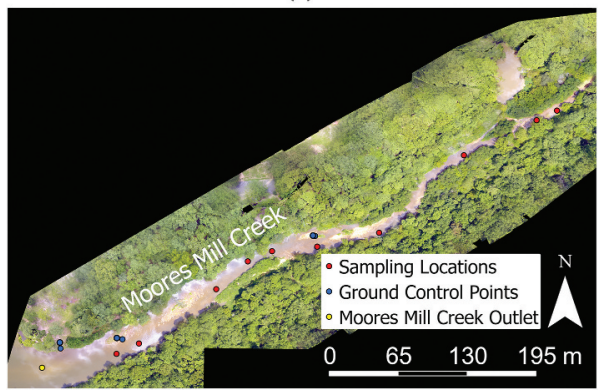

(b)

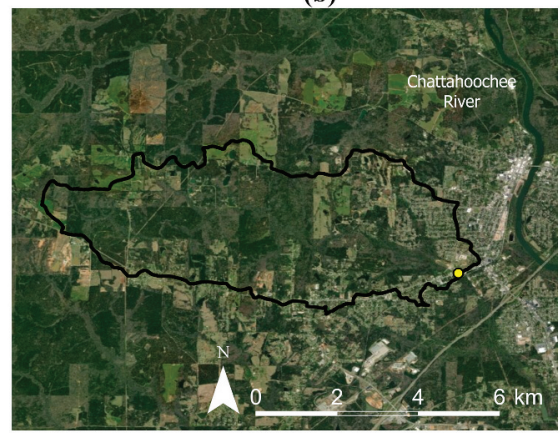

(d)

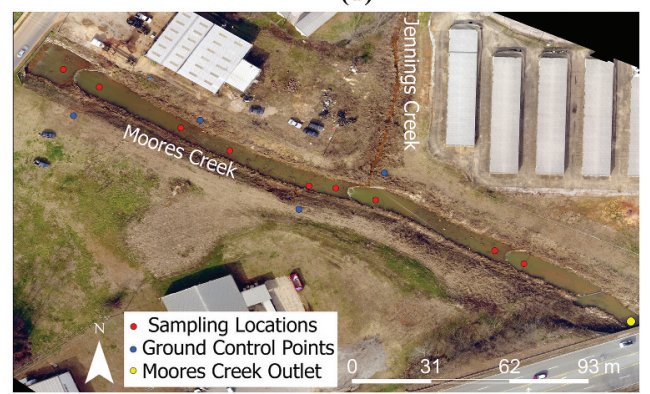

Figure 3. Overview of sample site locations:(a) The Moores Mill Creek watershed, with the outlet located at the inflow of Chewacla Lake in Chewacla State Park in Auburn, AL, USA; (b) the Moores Creek watershed, with the outlet located at the Veterans Memorial Parkway bridge in Lanett, AL, USA; (c) the Moores Mill Creek (Chewacla) reach with sampling locations denoted; (d) the Moores Creek (Lanett) reach with sampling locations denoted.

Table 1. sUAS platform specification (DJ 2019; Sequoia 2019).

\begin{tabular}{lccll}
\hline & Aircraft & \multicolumn{2}{c}{ Sensor } & \multicolumn{2}{c}{ Band span $(\mathrm{nm})$} \\
\hline Weight $(\mathrm{g})$ & 1380 & 72 & Green: & 480 to 520 \\
& & & Red: & 640 to 680 \\
Size $(\mathrm{mm})$ & 350 & $59 \times 41 \times 28$ & Red Edge: & 730 to 810 \\
& & & Near-infrared: & 770 to 810 \\
\hline
\end{tabular}

referencing during water sampling. For each flight, three ground control point (GCP) targets were placed at various locations along the Lanett reach (Figure 3(d)). GCPs were used to significantly increase the geospatial accuracy of the imagery (Gauci et al. 2018). The location of the GCPs were selected by ensuring an even horizontal distribution while accounting for vertical undulations and confirming a clear view of the sky. The location of each GCP target and water sampling location was measured and recorded using a Trimble Geo7x running TerraSync (Trimble Navigation Limited, Westminster, CO, USA) rated at a $1 \mathrm{~cm}$ accuracy. The sUAS was then flown over the study site with a side and front overlap of $80 \%$ at $76 \mathrm{~m}$ altitude, followed by water sampling beginning with the most downstream location. At each sampling location (Figure 3(d)), water depth was measured and then $500 \mathrm{ml}$ water samples were collected from the surface, middle and bottom of the water column using a depth integrated water sampler (Forestry Suppliers, Jackson, MS, USA). Samples collected at the bottom of the water column were collected approximately $2.5 \mathrm{~cm}$ from the 
streambed. If the water depth was less than $40 \mathrm{~cm}$, only a surface water sample was collected. Samples were collected in order from downstream to upstream so as not to collect sediment that was disturbed while walking to each sample location (Figure 3(d)). A total of nine locations were sampled with 18 samples collected on each field date. Please see the supplemental material for all sampling depths. Bed sediment samples were also collected and processed for grain size analysis following Gee and Bauder (1986) procedure.

Data collection at Chewacla State Park was conducted on 25 July 2019. No previous rain events were closely recorded when sampling occurred since 20 July 2019. Three GCP targets were placed along the stream where there was no canopy cover (Figure 3(c)). These locations were measured following the same methods used at the other sample site. The sUAS was then flown over the study site with a side and front overlap of $85 \%$ at $76 \mathrm{~m}$ altitude. Water sampling began at Chewacla Lake and continued upstream at locations where there was no canopy cover or existing overshadowing (Figure 3(c)). The location of each water sample was measured and recorded by using the laser range finder on the Trimble Geo7x in order to offset the position to the actual sample location. Water and sediment sampling followed the same protocol as at the other sample site.

\subsection{Data processing}

Water samples were brought to the laboratory and processed for turbidity and TSS. TSS was measured following the United States Environmental Protection Agency (USEPA) Method 160.2 (USEPA 1971). Each filter $\left(\right.$ Whatman $^{\circledR}$ glass microfiber filters, Grade 934$\mathrm{AH}^{\circledast} \mathrm{RTU}$ ) was pre-rinsed, dried and weighed. Each sample was shaken to resuspend sediments and $250 \mathrm{ml}$ was suctioned through a filter, which was removed from the filtering apparatus and placed in a drying oven $\left(103^{\circ} \mathrm{C}\right)$ until constant weight was achieved. Turbidity was measured following USEPA Method 180.1 (USEPA 1993). A Hach $2100 \mathrm{Q}$ turbidimeter (Hach, Loveland, CO, USA) was first calibrated following manufacturer instructions. The water sample was then thoroughly mixed and poured into a glass sample vial for placement in the turbidimeter. Four turbidity measurements were averaged for each water sample. All measurements were under $40 \mathrm{NTU}$, so no samples required dilution.

For multispectral imagery processing, Pix4D (Pix4D, Prilly, Switzerland) was used for radiometric calibration, importing and locating GCPs and orthomosaic map construction. Atmospheric correction was not applied since the sUAS was flown at an altitude of $76 \mathrm{~m}$ which is a small atmospheric column, especially when compared to satellite atmospheric columns. Because such a low altitude was used, the discrepancy of radiance at the sensor and at the water surface is negligible and so it was ignored (lqbal, Lucieer, and Barry 2018). Pixel values for each band were then determined by using the recorded locations for each water sample and the zonal statistics tool in ArcGIS (ESRI, Redlands, CA, USA).

\subsection{Statistical analysis}

To develop unique TSS and turbidity models for small streams, correlation tests between turbidity and band pixel values and between TSS and band pixel values were conducted for all single bands and possible band ratio: $G, R, R E, N I R, G / R, G / R E, G / N I R, R / G, R / R E, R / N I R$, $\mathrm{RE} / G, \mathrm{RE} / R, \mathrm{RE} / \mathrm{NIR}, \mathrm{NIR} / G, \mathrm{NIR} / R$ and NIR/RE. Correlation tests were conducted for the 
Lanett data considering all water samples, averaged water column value, all water samples excluding the rain event dataset, and averaged water column excluding the rain event dataset. The averaged water column value was calculated by averaging the water sample measurements from the surface, middle and bottom of the water column.

From the correlation analyses, four single bands and/or band ratios were identified that had the highest significant correlation coefficients ( $r$-values) for turbidity and TSS. These four band variables were then used with a stepwise linear regression procedure to determine the combination that produced the highest coefficients of determination $\left(R^{2}\right)$ values while including only model variables with probability $(p)$ value $<0.05$. Once the best models were selected for each scenario, each model was tested for overfitting by taking out $20 \%$ of the data and reprocessing it through the stepwise linear regression. The revised model was fit to the removed data points and was deemed not to be overfit if the $R^{2}$ value for the removed data was within 0.1 of the $R^{2}$ for the original model. Additionally, root mean square error (RMSE), residual prediction deviation (RPD) and mean normalized bias (MNB) were also calculated using Equation $(1-3)$, respectively.

$$
\begin{gathered}
\text { RMSE }=\sqrt{\frac{\sum_{i=1}^{n}\left(P_{i}-O_{i}\right)^{2}}{n}} \\
\operatorname{RPD}=\frac{\sigma_{0}}{\left(\operatorname{RMSE}_{p_{i}}\right)} \\
\operatorname{MNB}(\%)=\frac{1}{n} \sum_{i=1}^{n} \frac{\left(P_{i}-O_{i}\right)}{O_{i}} \times 100
\end{gathered}
$$

Where:

RMSE = root mean square error

$n=$ number of observations

$i=$ a value in a dataset

$\mathrm{P}_{i}=$ predicted value

$\mathrm{O}_{i}=$ observed value

$\mathrm{RPD}=$ residual prediction deviation

$\sigma_{0}=$ standard deviation of the observed variable

$\mathrm{RMSE}_{\mathrm{P}_{\mathrm{i}}}=$ root mean square error of the predicted value

$\mathrm{MNB}=$ mean normalized bias

To ensure sample size was adequate, a procedure based on the noncentral (NC) $F$ distribution was used to determine the statistical power of each of the multiple regression models developed (Cohen and Nee 1987). For a model with sample size $n$ and $k$ independent variables, the statistical power $(1-\beta)$ of the model is determined by calculating the probability of type II error using Equation (4). The noncentral parameter $(\lambda)$ was calculated using Equation (5). The Cohen's effect size $\left(f^{2}\right)$ was calculated using Equation (6). A statistical power of 0.8 was considered adequate.

$$
\begin{gathered}
\beta=\left(F_{N C}\right)\left(\left(F_{\text {crit }}\right) \mid\left(D \circ F_{\text {Reg }}\right),\left(D o F_{\text {Res }}\right), \lambda\right) \\
\lambda=\mathrm{f}^{2} \mathrm{n}
\end{gathered}
$$




$$
f^{2}=\frac{R^{2}}{1-R^{2}}=\frac{\left(S S_{\text {Reg }}\right)}{\left(S S_{\text {Res }}\right)}
$$

Where:

$\mathrm{F}_{\text {crit }}=F$ critical value of the regression model

DoF $_{\text {Reg }}=$ regression degrees of freedom, equal to $k$

$\mathrm{DoF}_{\mathrm{Res}}=$ residual degrees of freedom, equal to $(n-k-1)$

$\left(F_{N C}\right)\left(\left(F_{\text {crit }}\right) \mid\left(D_{\text {oo }} F_{\text {Reg }}\right),\left(D_{\text {oo }} F_{\text {Res }}\right), \lambda\right)=$ the cumulative distribution function of the noncentral $F$ distribution

$\lambda=$ noncentral parameter.

$\mathrm{f}^{2}=$ Cohen's effect size

$\mathrm{SS}_{\text {Reg }}=$ regression sum of squares

$\mathrm{SS}_{\text {Res }}=$ residual sum of squares

In order to determine if models developed from a stream can be used to predict TSS and turbidity of another stream, Chewacla pixel values were inputted into the Lanett models. The TSS and turbidity model results were then compared to actual measurements. All statistical analyses were performed in Statistical Analysis System (SAS) (SAS 1982, 1985) and Matlab 2020a (Mathworks, Natick, MA, USA).

\section{Results}

\subsection{Turbidity and TSS}

Turbidity and TSS sampling results from Lanett, AL demonstrated a range of values that varied by sampling date. Based on a developed rating curve, flow rates for February, March and July sample sets were $0.97 \mathrm{~m}^{3} \mathrm{~s}^{-1}, 0.98 \mathrm{~m}^{3} \mathrm{~s}^{-1}$ and $0.94 \mathrm{~m}^{3} \mathrm{~s}^{-1}$, respectively. The 10 July 2019 sampling date generally had higher turbidity and TSS measurements (Figure 4), with increases at sampling locations directly downstream of either the cross vanes, J hook or riffle. The increase at approximately $75 \mathrm{~m}$ can be attributed to an inflowing pipe that drains an adjacent field. Surface TSS measurements for the March sample set were slightly higher than the July sample set (Figure 4(c)), while the July sample set had higher TSS readings at the middle and bottom of the water column (Figure $4(e, g)$ ) due to the rain event that occurred eight hours before sampling. The elevated surface TSS values for the March sample set enabled the average water column results to be above the July rain event sample set (Figure 4(a)). For turbidity measurements, the July rain event sample set was mostly higher than the other two datasets. Inflections at locations of the in-stream structures were also present, but less pronounced. Findings also indicated that turbidity measurements from the middle and bottom of the water column for February and March datasets were in close agreement and represent turbidity at low flow (Figure $4(f, h)$ ). The close range of surface turbidity of all three sample sets (Figure 4(d)) and elevated middle and bottom water column measurements in July (Figure $4(f, h)$ ) generally indicated deposition of suspended solids from surface to streambed. The bed sediment samples were classified according to the USDA soil texture classification as sand ( $99.7 \%$ sand, $0.3 \%$ silt or clay). 

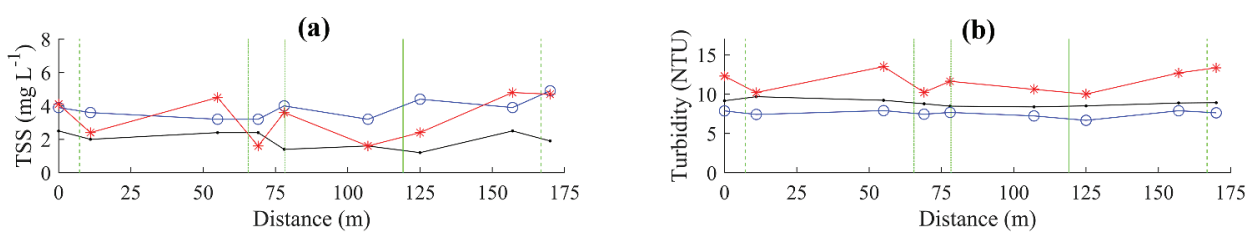

(c)
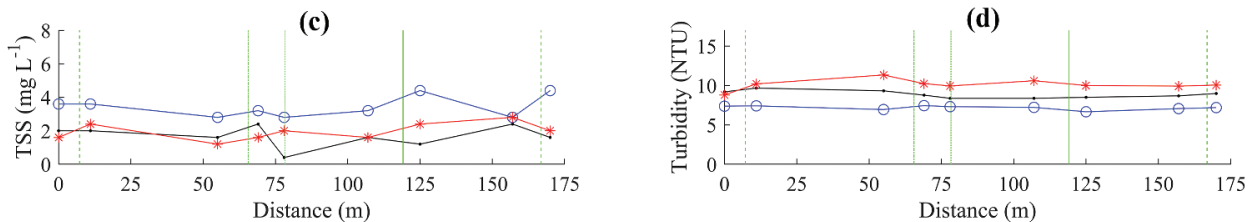

(e)
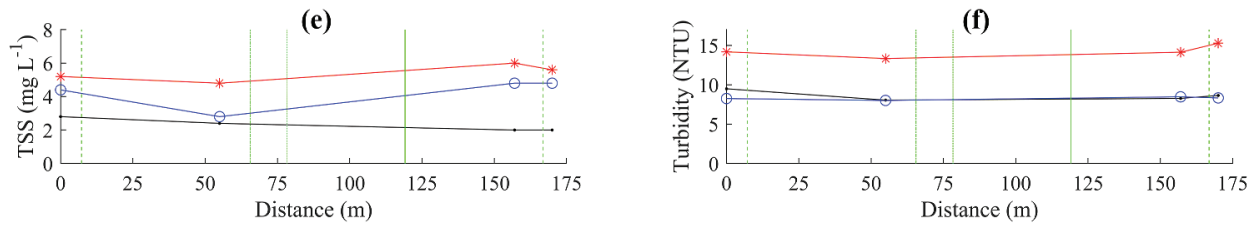

(g)
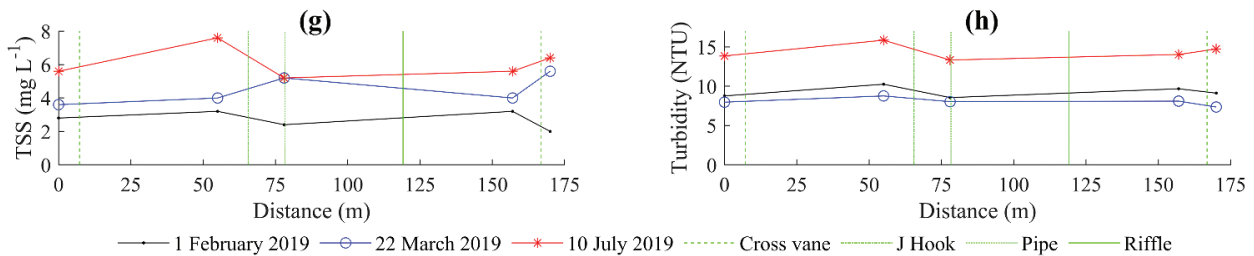

Figure 4. TSS and turbidity at Lanett, $A L$, in 2019 with $175 \mathrm{~m}$ being furthest upstream: (a) averaged TSS of water column, (b) averaged turbidity of water column, (c) TSS of the water surface, (d) turbidity of the water surface, (e) TSS of the middle of the water column, (f) turbidity of the middle of the water column, (g) TSS of the bottom of the water column, (h) turbidity of the bottom of the water column.

\subsection{Previous model comparison and regression model development}

To determine if models for predicting TSS from multispectral data for rivers are applicable to small streams, the performance of the regression models developed by Larson et al. (2018) for the Maumee River were tested for the data from this study. Equations (7) and (8) were developed by Larson et al. (2018) for TSS at depths of 0 to $15 \mathrm{~cm}$. Equation (7) was developed from aggregated field spectroradiometer data, while Equation (8) was developed using sUAS multispectral imagery in Larson et al. (2018) study. Equations (7) and (8) were tested using the Lanett pixel values from collected imagery. As seen in Table 2, results from Equations (7) and (8) yielded TSS readings that were much higher than any recorded TSS measurement. All other models from Larson et al. returned results that were negative or much higher than measured results. This comparison indicates that new models should be developed since existing model results were a poor predictor of measured values.

Table 2. Comparison of measured TSS ( $\mathrm{mg} \mathrm{L}^{-1}$ ) to Larson et al. (2018) models developed from spectroradiometer and sUAS multispectral sensor data.

\begin{tabular}{lccc}
\hline Date & Mean measured TSS & Spectroradiometer & sUAS \\
\hline 01 February 2019 & 2.0 & 57.9 & 49.5 \\
22 March 2019 & 3.8 & 48.9 & 60.9 \\
10 July 2019 & 3.3 & 59.7 & 76.9 \\
\hline
\end{tabular}




$$
\begin{gathered}
\mathrm{TSS}=-151.2+(384 \times(\mathrm{RE}))+\left(173.9 \times\left(\frac{\mathrm{G}}{\mathrm{R}}\right)\right) \\
\mathrm{TSS}=142.7-\left(53.8 \times\left(\frac{\mathrm{R}}{(\mathrm{RE})}\right)\right)
\end{gathered}
$$

Where:

TSS $=$ total suspended solids $\left(\mathrm{mg} \mathrm{L}^{-1}\right)$

$\mathrm{RE}=$ red edge $(730 \mathrm{~nm}$ to $740 \mathrm{~nm})$

$R=\operatorname{red}(640 \mathrm{~nm}$ to $680 \mathrm{~nm})$

$G=$ green (480 $\mathrm{nm}$ to $520 \mathrm{~nm}$ )

Initial analysis was conducted with TSS and turbidity values from all sampling dates. Separate models were developed with values averaged over the water column and with samples from different depths treated as unique data points. Using the correlation procedure, four single bands and/or band ratios with the highest $r$-values and lowest $p$-values were identified (i.e. band, $r$ and $p$-value rows in Table 3). All possible combinations (ranging from one variable to all four variables) of the selected four band and/or band ratios were then inputted as predictive variables in linear regressions. Model results from linear regressions can be found in Table 3 . The best $R^{2}$ results were those that included all identified variables. Compared to turbidity, $R^{2}$ values were smaller and $p$-values were larger for both TSS models, indicating that turbidity has a stronger and more significant relationship with multispectral data. Overfitting was checked and deemed insignificant, such that the $R^{2}$ values were within 0.1 of the original model $R^{2}$. These findings were reinforced by linear regression values and comparisons of modelled predictions and measurements (Figure 5). Modelled TSS and turbidity maps were generated for each model (Figure 6).

A second analysis without the rain event dataset was conducted to determine if separate high flow and low flow models would provide better results. By excluding the high flow dataset, $R^{2}$ values for both TSS models improved, while $R^{2}$ values for both turbidity models decreased (Table 4). It should also be noted that some band ratios and single bands used in each model were different, such that the turbidity models have more significance for green when rain event data was excluded. Overfitting was checked and deemed insignificant, such that the $R^{2}$ values were within 0.1 of the original model $R^{2}$. These findings were further examined by linear regression values and comparisons of modelled predictions and measurements (Figure 7). Modelled TSS and turbidity maps were generated for each model (Figure 8).

\subsection{Cross-site model testing}

To determine if models developed with Lanett data can be used on similar streams, sUAS imagery and sampling was conducted on Moores Mill Creek in Chewacla State Park, AL, USA. Pixel values from Chewacla were inputted into the models and results were compared to measurements (Figure 9). Modelled results had very low correlation with measured TSS and turbidity values. This suggests that site-specific models should be developed for monitoring purposes. The bed sediment samples were classified by the USDA soil texture classification as sand $(99.0 \%$ sand, $0.5 \%$ silt, $0.5 \%$ clay). 


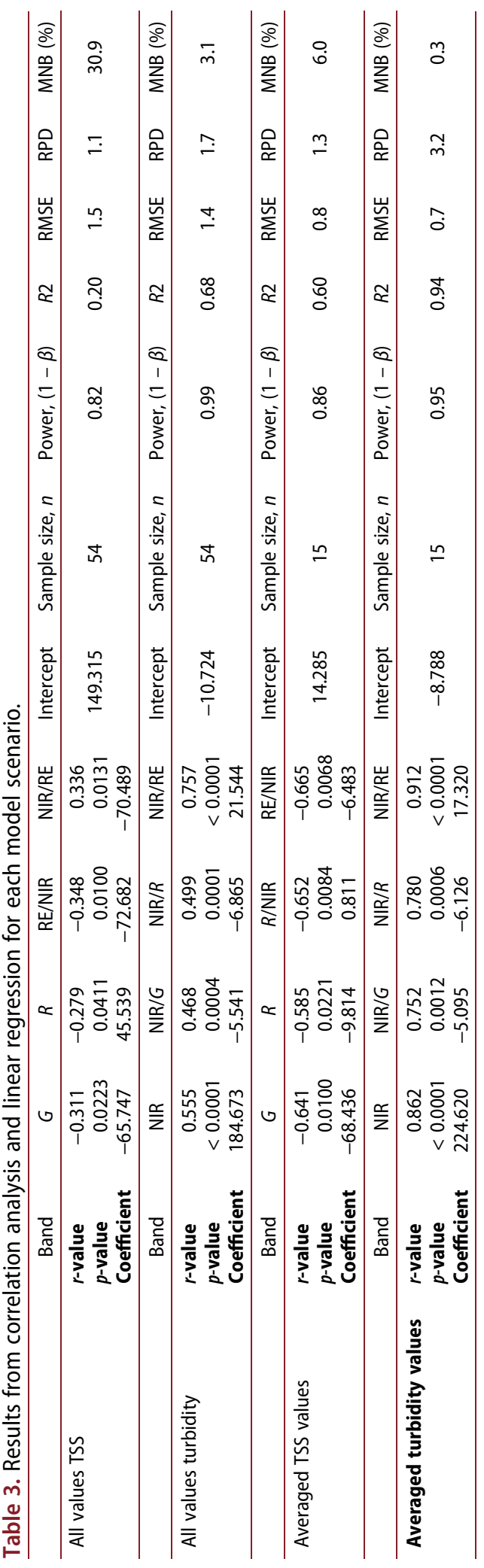



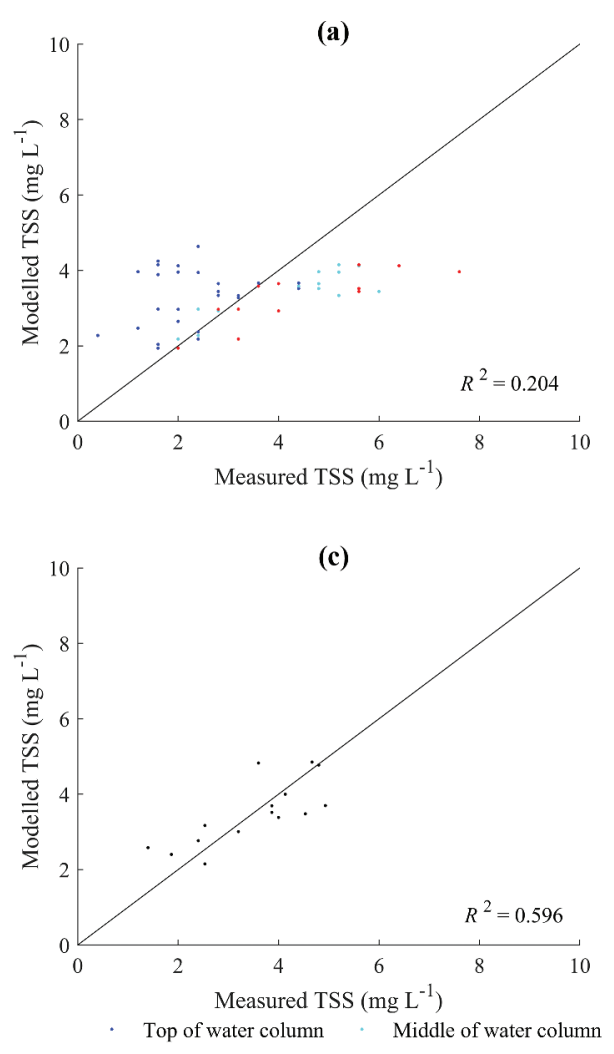

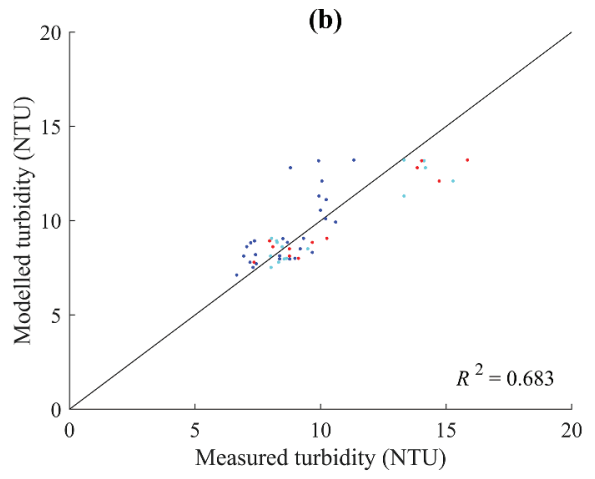

(d)

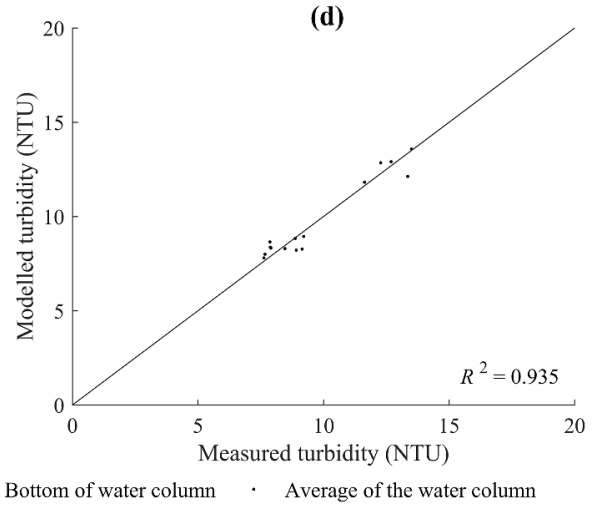

Figure 5. Scatter plots of measured TSS and turbidity and modelled results: (a) all measured TSS values and modelled TSS values, (b) all turbidity values and modelled turbidity values, (c) averaged water column TSS values and modelled averaged water column TSS values, (d) averaged water column turbidity values and modelled averaged water column turbidity values.

To ensure that the conclusion of poor cross-site model performance was not due to small sample size, the statistical power of the analysis was estimated in MATLAB 2020a (MathWorks, Natick, MA, USA) using a Monte Carlo simulation $(N=10000)$. For the model based on averaged water column values, which had the smallest sample size of 9 , the estimated power to detect a correlation of 0.71 was 0.75 ( $95 \%$ confidence interval 0.72 to 0.77 ). This correlation value represents an $R^{2}$ value of 0.5 , a reasonable minimum standard for acceptable model performance. Significant correlations were also not detected in the analyses with a sample size of 21 . These would have been able to detect a correlation as low as 0.42 (corresponding to $R^{2}=0.18$ ) with power 0.7 ( $95 \%$ confidence interval 0.67 to 0.73 ). Therefore, statistical power was adequate from a model development perspective.

\section{Discussion}

The use of multiple bands and band ratios resulted in better $R^{2}$ values which agrees with other studies (Chen, $\mathrm{Hu}$, and Muller-Karger 2007; Larson et al. 2018). Spectral increase with more sediment is expected (Lodhi et al. 1998), but not as strong of a positive relationship 
(a)

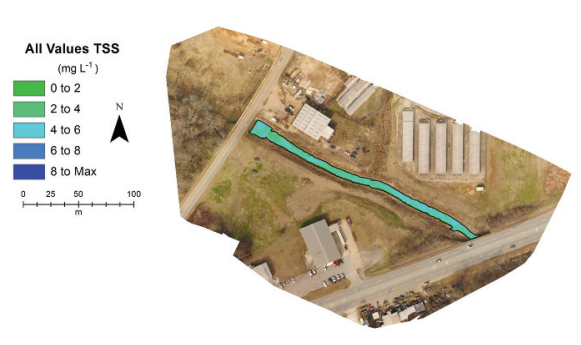

(c)

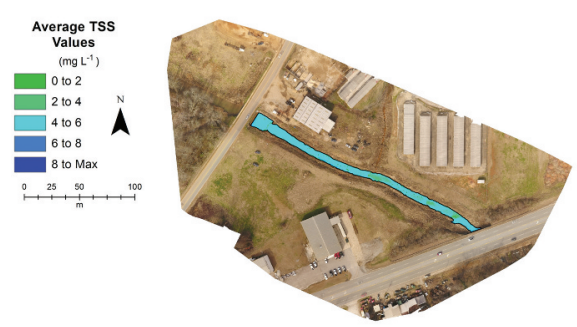

(b)

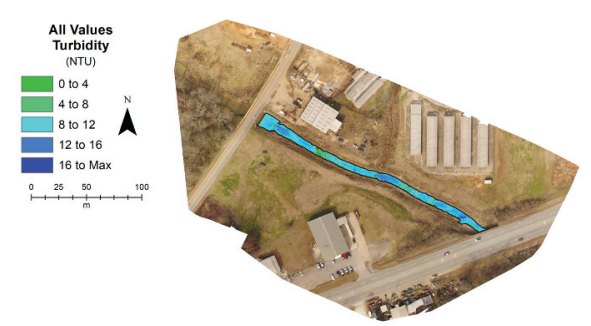

(d)

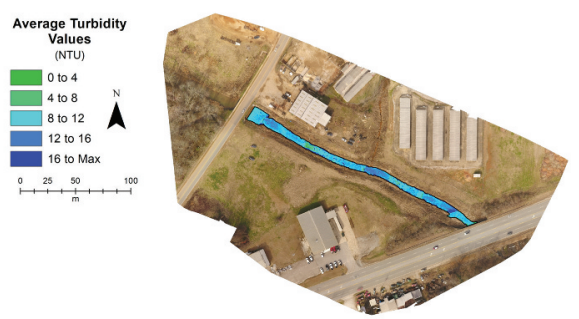

Figure 6. Generated sUAS TSS and turbidity maps from 10 July 2019: (a) all TSS values, (b) all turbidity values, (c) averaged water column TSS values, (d) averaged water column turbidity values.

was shown probably due to low suspended sediment levels. Low suspended sediment levels were only present during this study because sampling was not done directly after rain events due to safety concerns and location factors. Also, Moores Creek is a small watershed, so the duration of event hydrographs is short. Therefore, it was difficult to be at the site to sample during high flows when elevated suspended solids levels were present.

Comparison of the Larson et al. (2018) $15 \mathrm{~cm}$ depth models, developed from a sUAS multispectral sensor and from a spectroradiometer, to the Lanett TSS measurements showed that their models over-estimated the concentration, thus indicating that models developed for large rivers are not applicable to small streams. This discrepancy could be due to differences in both sediment type and water depth, both of which are discussed later in this section.

The separation of data collected within 8 hours of a precipitation event overall increased the $R^{2}$ values and decreased the $p$-values for the TSS models while also changing one of the band ratios. For turbidity models, separation of data based on precipitation events did not aid either the $R^{2}$ or $p$-values and completely changed the significant bands and band ratios. Even though significant bands and band ratios did change, each $r$ and $p$-value were close to the all values dataset or individually less significant. Overall, $R^{2}$, RMSE, and RPD agree closely as to which models perform well. Generally, RPD $>2$ indicates a reliable model (Chang et al. 2001). MNB indicated that the models tend to overpredict, especially for TSS models and models with values after rainfall. This overprediction can easily be seen in the corresponding sediment maps (Figure 8(ad)), where dark blue represents modelled values greater than 


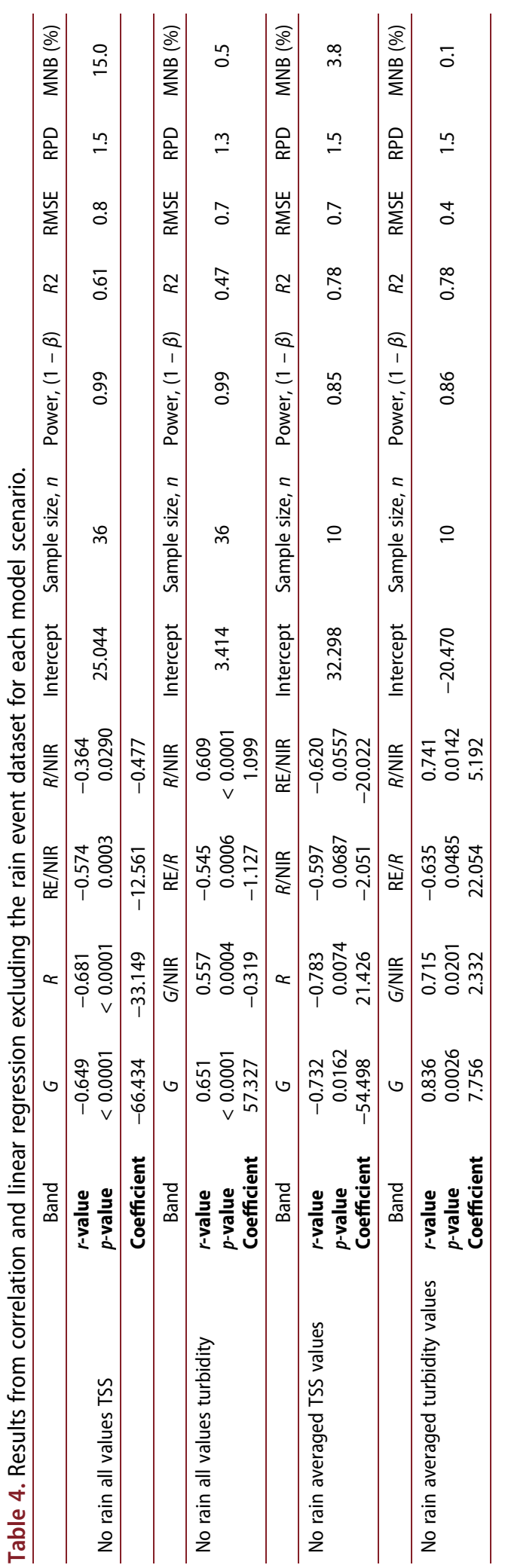



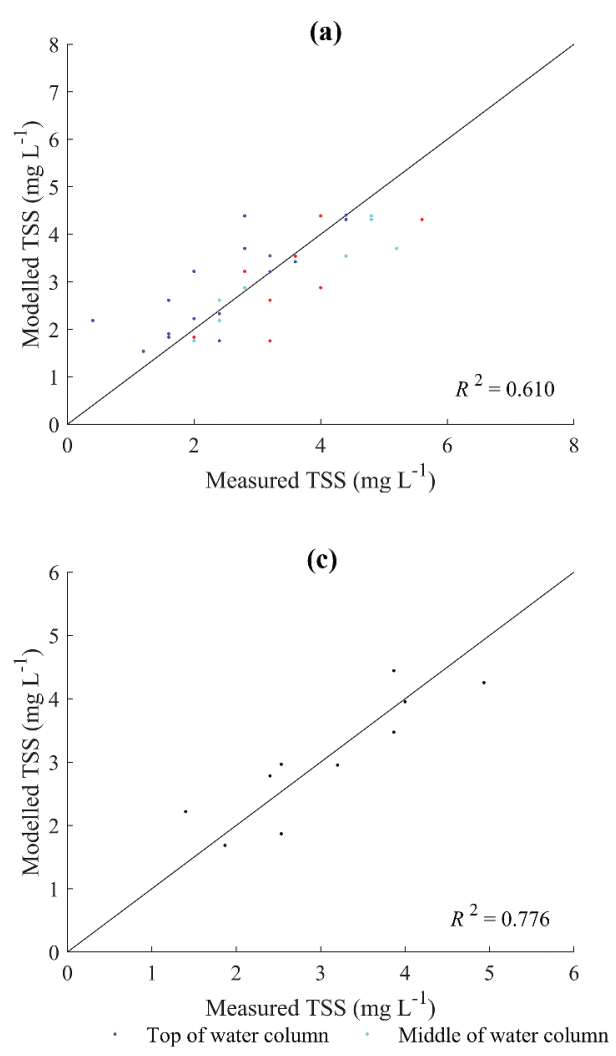

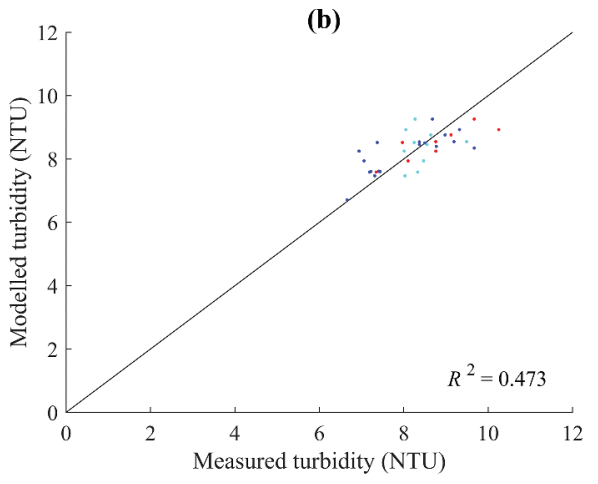

(d)

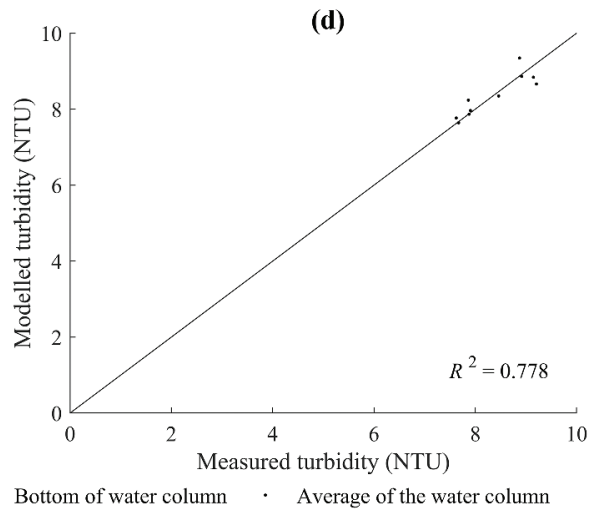

Figure 7. Scatter plots of measured TSS and turbidity and modelled results excluding rain event data: (a) no rain TSS values and no rain modelled TSS values, (b) no rain turbidity values and no rain modelled turbidity values, (c) no rain averaged water column TSS values and no rain modelled averaged water column TSS values, and (d) no rain averaged water column turbidity values and no rain modelled averaged water column turbidity values.

what was measured. Additionally, some models failed to produce the diversity of measured values when applied to multispectral imagery (Figures $6(a, c)$ and $8(b, c))$. Another obvious issue with the maps (Figures 6 and 8 ) is that the models have difficulty with shallow water along the banks and in-stream structures, both of which are shown as high values in most of the maps. Certain models are able to show spatially reasonable measurements throughout the stream (Figure $6(b, d)$ ), while others show expected spatially variable measurements, but suffer from erroneously high values (Figure $8(a, d)$ ). From the TSS and turbidity maps (Figures 6 and 8), values are present that are much higher than what was measured (dark blue). Due to this, interpretation should be cautioned, since extrapolation of the regression models are being used outside of the bounds of the measured data.

Results from Tables 3 and 4 suggest that high and low flow models should be developed for both TSS and turbidity monitoring. Turbidity is an optical parameter of water since it is the measurement of light scattered by the suspended material (Gregory 1985). Turbidity's optical dependence could be a reason why it is more easily modelled using multispectral imagery since the light that is not absorbed by water is assumed to be reflected back by suspended particles. Turbidity has been repetitively used to 
(a)

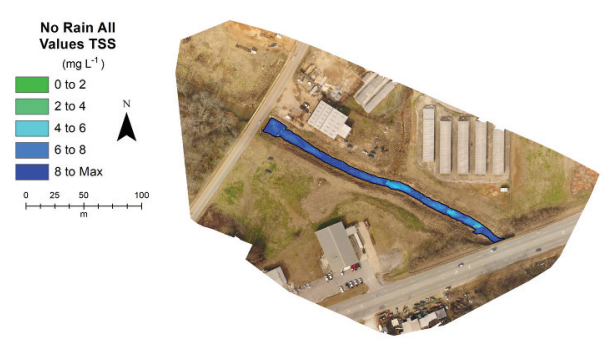

(c)

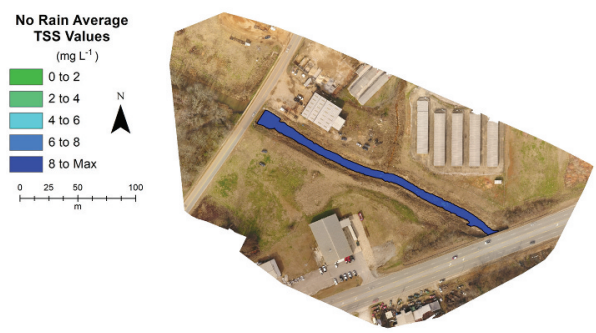

(b)

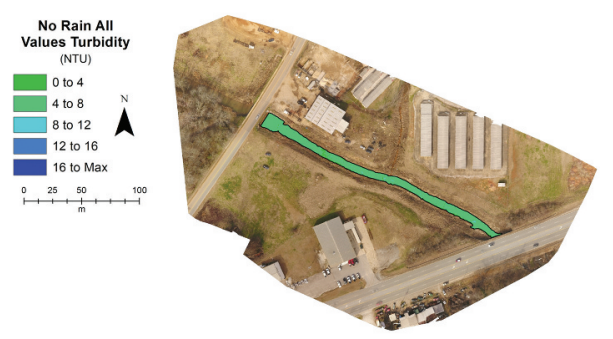

(d)
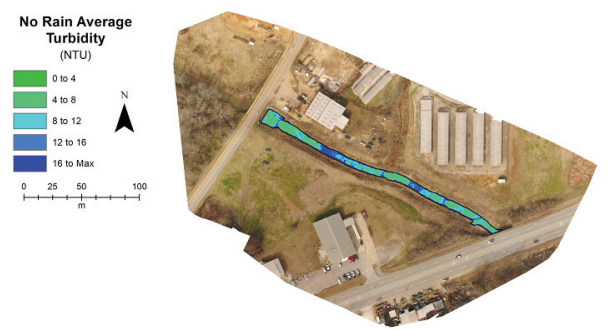

Figure 8. Generated sUAS TSS and turbidity maps excluding rain event data from 10 July 2019: (a) no rain TSS values, (b) no rain turbidity values, (c) no rain averaged water column TSS values, and (d) no rain averaged water column turbidity values.

estimate TSS by developing a rating curve. This has been done in several types of water bodies since it is much less labour- and time-intensive to measure turbidity than TSS (Mitsch and Reeder 1992; Packman, Comings, and Booth 1999; Gippel 1989; Halfman and Scholz 1993; Paul, Kasprzyk, and Lick 1982; Christensen, Ziegler, and Jian 2001).

One improvement for estimating TSS and turbidity measurements in small streams is to account for streambed reflectance. Due to the relatively low suspended solids and water depth, the streambed was visible. Water depth barely reached over a metre at the deepest pools and was less than $0.4 \mathrm{~m}$ at the shallowest runs. Depth was not included as a variable in any of the models tested since the objective of the study was to investigate if only a multispectral sUAS flight could be used for detection and/or monitoring of TSS and turbidity measurements of small streams. In (Chen, Chuanmin, and Muller-Karger 2007) Tampa Bay turbidity study, pixels with water depth less than $2.8 \mathrm{~m}$ were excluded due to decreased relationship between $645 \mathrm{~nm}$ reflectance and turbidity. A similar approach could be taken, but with a decreased threshold. Also, integration of sUAS bathymetry measurements has the possibility to increase the accuracy of predicting TSS and turbidity through several methods using structure from motion and combination of light detection and ranging (LiDAR) with multispectral imagery (Dietrich 2017; Hilldale and Raff 2008; Legleiter 2012). This would allow for a complete and inclusive sUAS assessment of the reach that considers water depth.

The comparison of the Lanett model predictions to actual Chewacla measurements showed that for at least this instance, site specific models are required. One factor that 

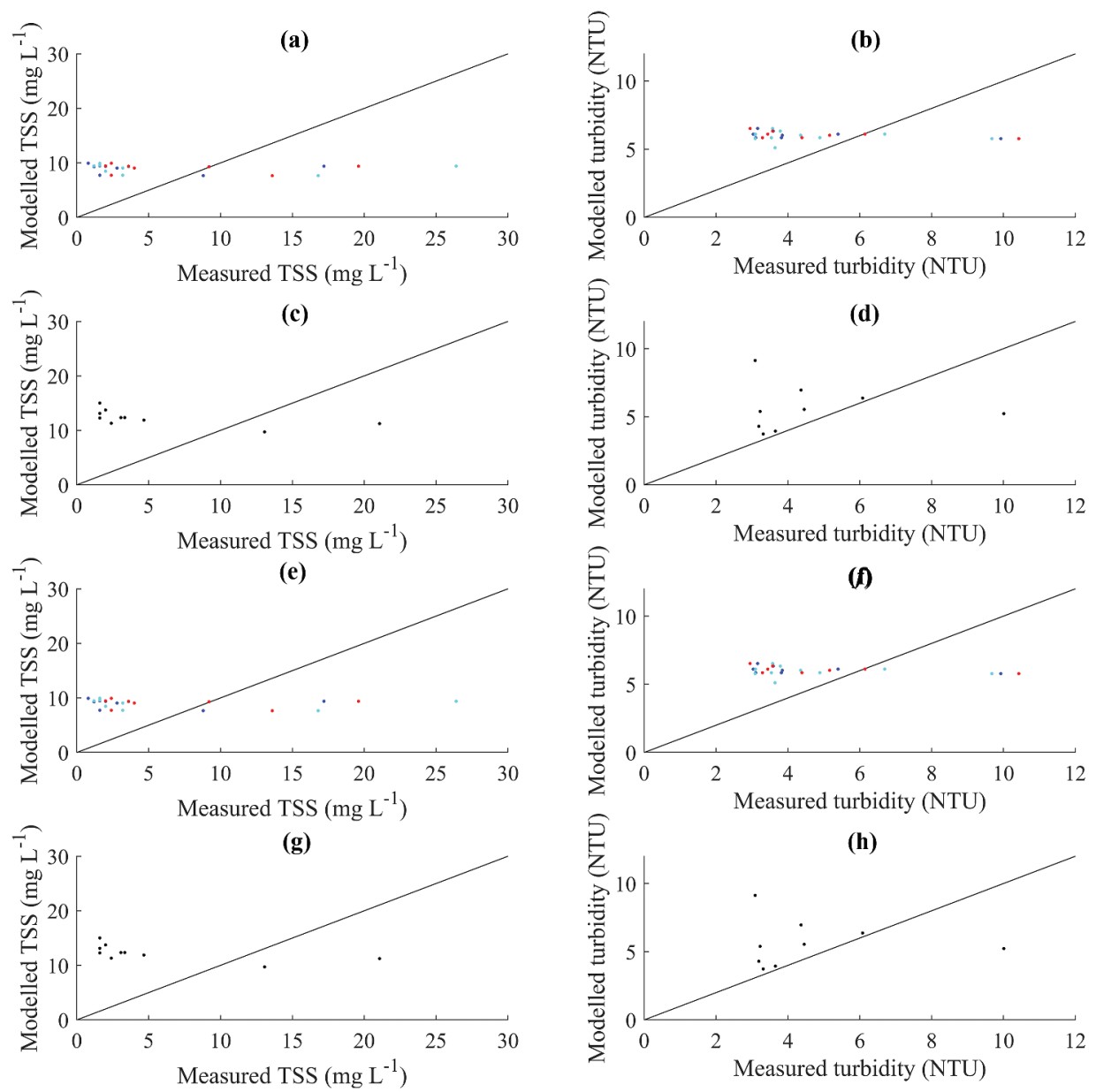

Average of the water column . Top of water column

Middle of water column $\quad$ B Bottom of water column

Figure 9. Scatter plots comparing measured Chewacla TSS and turbidity and modelled TSS and turbidity using the developed Lanett models: (a) all values TSS Lanett model against measured Chewacla TSS, (b) all values turbidity Lanett model against measured Chewacla turbidity, (c) averaged TSS Lanett model against measured averaged Chewacla TSS, (d) averaged turbidity Lanett model against measured averaged Chewacla turbidity, (e) all values no rain TSS Lanett model against measured Chewacla TSS, (f) all values no rain turbidity Lanett model against measured Chewacla turbidity, (g) no rain averaged TSS Lanett model against measured average Chewacla TSS, (h) no rain averaged turbidity Lanett model against measured averaged Chewacla turbidity.

could have caused this is the different bed sediment compositions of the two sites that could have affected the type of suspended solids in the water column. However, both bed materials are primarily made up of sands, so if there were discrepancies with respect to the type of suspended solids present between sites, it is probably due to upstream characteristics and inputs. Sampling started upstream at the lake where there was primarily silt on the bed and quickly changed to a sand stream bed. The presence of silt in the lake could indicate that primarily silt was suspended in the Chewacla dataset. Although no spectral measurements of different types of sediment were collected in this study, perhaps the silt content could have reflected differently than the clay particles 
present in the Lanett dataset (Debret et al. 2011; Barthod et al. 2015). As with the Lanett sampling, depth was also not considered though the Chewacla dataset did have a smaller range of depths of $0.59 \mathrm{~m}$ where Lanett had a range of $0.88 \mathrm{~m}$. Another aspect to consider between the two sites, is that the Lanett site was recently restored and has a much more uniform physical structure consisting of the in-stream structures along with the pools after each structure. The Chewacla site has been formed by more natural processes as is evident by visual inspection of the aerial map which shows variable channel width, sand bars, large woody debris, dunes and islands of vegetation. These fundamental fluvial geomorphic differences could have caused the discrepancy in the comparison.

With this data collection and analysis, there are some uncertainties that should be mentioned. Data collection of water samples after the sUAS flight were collected as quickly as possible, but there was a delay for the most upstream samples, since sequential sampling order from downstream to upstream is necessary so to not disturb bed sediment that could affect downstream samples. This data sampling delay could have allowed for TSS and turbidity levels to change as well as water surface roughness, stream discharge and water depth. Additionally, water samples taken approximately $2.5 \mathrm{~cm}$ from the streambed could have potentially collected bed load particulate matter that might have influenced TSS and turbidity measurements. Collected imagery could have been impacted by water surface reflectance/glint, surface water roughness which can backscatter more light, and atmospheric particle presence. Visual inspection of the Chewacla imagery reveals that there was evidence of surface reflectance and, in certain areas, water surface roughness that might have affected the model comparison. Another water quality aspect that should be considered is coloured dissolved organic matter (CDOM) since high amounts of CDOM results in low reflectance (Menken, Brezonik, and Bauer 2006). CDOM levels in fresh water are usually elevated and thus could have negatively influenced the models which are dependent on increased spectral response with increased sediment concentrations. Also, it should be noted that this study only has three sample sets that were used to develop models for predicting TSS and turbidity and one sample set to judge these models on another stream.

Future studies should incorporate more data collection to encompass seasonal variability along with more low and high flow events with focus on detecting high levels of suspended sediments since it is more important for monitoring. A model at higher flows could lead to more suspended solids thus increasing reflectance. This could lead to better detection and accuracy of TSS and turbidity at high sediment concentration levels. Additionally, since linear regression has proven to be limiting, the use of machine learning and neural networks should also be included in future studies, as seen in Sharaf El Din, Zhang, and Suliman (2017). Also, future studies should compare results from multispectral imagery and hyperspectral imagery, since narrower band widths and the use of the blue band would be expected to better represent sediment concentrations.

This study shows the potential of using sUAS to monitor TSS and turbidity for small streams while giving more insight into using financially accessible technology for holistic stream sediment monitoring. Findings reveals that site-specific models are most likely needed in addition to accounting for depth of water and flow event. 


\section{Conclusion}

This study expanded on previous research to determine if sUAS multispectral imagery could be used to predict and monitor TSS and turbidity levels in small streams. All the TSS regression models developed by Larson et al. (2018) from spectroradiometer and from multispectral sUAS imagery were tested. All models either returned negative values or values much higher than what was actually measured. This showed that new models for small streams needed to be developed. First, models using all samples in addition to using the average of water column were developed. Next, models excluding the precipitation event data as well as using the average of the water column without the precipitation event data were developed. By excluding the precipitation event data, the $R^{2}$ increased, the $p$-value decreased and one of the band ratios changed for the TSS models. The exclusion of the precipitation data did the opposite to the $R^{2}$ and $p$-values and changed all the significant single bands and band ratios for the turbidity models. These findings suggest that low flow and high flow models potentially need to be separately developed in order to predict/monitor both TSS and turbidity. Lastly, the pixel values collected from Chewacla State Park were inputted into the developed models and the modelled results were then compared to the in situ water measurements from Chewacla. There was very low correlation, suggesting that site-specific models are required.

Some improvements are possible to further increase model accuracy. Streambed reflectance in streams with low suspended solids levels and shallow depths should be incorporated into the models. Accounting for depth and stream bathymetry in the models might offset the effects of streambed reflectance. Additionally, the suspended solids between the two sites could have reflected differently if one site had primarily suspended clays while the other had silts. Accounting for the composition of the suspended solids could also improve predictions. This study has shown that there are correlations between multispectral imagery and TSS and turbidity levels in small streams, but currently imagery alone will not be able to predict these measurements with high accuracy. Incorporating machine learning, water depth, narrower band widths and more sample sets are the necessary next steps for water quality remote sensing of small streams.

\section{Acknowledgements}

This study was funded by the Auburn University Office of Undergraduate Research, Auburn University $100+$ Women Strong and the Interdisciplinary Graduate Education Program in Remote Sensing at Virginia Tech. Thanks to the USDA-ARS National Soil Dynamics Laboratory, Auburn, AL for use of their laboratory vacuum filtration equipment.

\section{Disclosure statement}

No potential conflict of interest was reported by the authors.

\section{Funding}

This work was supported by the Auburn University Office of Undergraduate Research; Virginia Tech Interdisciplinary Graduate Education Program in Remote Sensing; Auburn University Samuel Ginn College of Engineering 100+ Women Strong. 


\section{ORCID}

Elizabeth M. Prior (D) http://orcid.org/0000-0001-7069-160X

\section{References}

Abia, A., C. James, E. Ubomba-Jaswa, and M. B. Momba. 2017. "Microbial Remobilisation on Riverbed Sediment Disturbance in Experimental Flumes and a Human-impacted River: Implication for Water Resource Management and Public Health in Developing Sub-saharan African Countries." International Journal of Environmental Research Public Health 14 (3): 306. doi:10.3390/ ijerph14030306.

ADEM, Alabama Department of Environmental Management. 2018. "Alabama Nonpoint Source Management Program 2018 Annual Report." Montgomery, AL 36130-1463: Alabama Dept. of Environmental Management Office of External Affairs Nonpoint Source Unit.

ADEM, Alabama Department of Environmental Management. 2019. Alabama Department of Environmental Management Water Division - Water Quality Program Volume 1 Division 335-6, In, edited by. Montgomery, Alabama: Alabama Department of Environmental Management.

Bailey, G. W., and T. E. Waddell. 1979. "Best Management Practices for Agriculture and Silviculture: An Integrated Overview." In Cornell Agricultural Waste Management Conference, 33-56. Ithaca, NY.

Barthod, L. R. M., K. Liu, D. A. Lobb, P. N. Owens, N. Martínez-Carreras, A. J. Koiter, E. L. Petticrew, G. K. McCullough, C. Liu, and L. Gaspar. 2015. "Selecting Color-based Tracers and Classifying Sediment Sources in the Assessment of Sediment Dynamics Using Sediment Source Fingerprinting." Journal of Environmental Quality 44 (5): 1605-1616. doi:10.2134/jeq2015.01.0043.

Bash, J. S., and C. M. Ryan. 2002. "Stream Restoration and Enhancement Projects: Is Anyone Monitoring?" Environmental Management 29 (6): 877-885. doi:10.1007/s00267-001-0066-3.

Becker, R. H., M. Sayers, D. Dehm, R. Shuchman, K. Quintero, K. Bosse, and R. Sawtell. 2019. "Unmanned Aerial System Based Spectroradiometer for Monitoring Harmful Algal Blooms: A New Paradigm in Water Quality Monitoring." Journal of Great Lakes Research 45 (3): 444-453. doi:10.1016/j.jglr.2019.03.006.

Beman, J. M., K. R. Arrigo, and P. A. Matson. 2005. "Agricultural Runoff Fuels Large Phytoplankton Blooms in Vulnerable Areas of the Ocean." Nature Geosciences 434 (7030): 211.

Brando, V. E., and A. G. Dekker. 2003. "Satellite Hyperspectral Remote Sensing for Estimating Estuarine and Coastal Water Quality." IEEE Transactions on Geoscience Remote Sensing 41 (6): 1378-1387. doi:10.1109/TGRS.2003.812907.

Briggs, M. A., C. B. Dawson, C. L. Holmquist-Johnson, K. H. Williams, and J. W. Lane. 2018. "Efficient Hydrogeological Characterization of Remote Stream Corridors Using Drones." Hydrological Processes 33 (2): 316-319.

Brown, T. C., and P. Froemke. 2012. "Nationwide Assessment of Nonpoint Source Threats to Water Quality." BioScience 62 (2): 136-146. doi:10.1525/bio.2012.62.2.7.

Burton, G. A., D. Gunnison, and G. R. Lanza. 1987. "Survival of Pathogenic Bacteria in Various Freshwater Sediments." Applied Environmental Microbiology 53 (4): 633-638. doi:10.1128/ AEM.53.4.633-638.1987.

Chang, C.-W., D. A. Laird, M. J. Mausbach, and C. R. Hurburgh. 2001. “Near-infrared Reflectance Spectroscopy-principal Components Regression Analyses of Soil Properties." Soil Science Society of America Journal 65 (2): 480-490. doi:10.2136/sssaj2001.652480x.

Chanson, H., D. Reungoat, B. Simon, and P. Lubin. 2011. “High-frequency Turbulence and Suspended Sediment Concentration Measurements in the Garonne River Tidal Bore." Estuarine Coastal Shelf Science 95 (2-3): 298-306. doi:10.1016/j.ecss.2011.09.012.

Chen, Z., H. Chuanmin, and F. Muller-Karger. 2007. "Monitoring Turbidity in Tampa Bay Using MODIS/Aqua 250-m Imagery." Remote Sensing of Environment 109 (2): 207-220. doi:10.1016/j. rse.2006.12.019. 
Christensen, V. G., A. C. Ziegler, and X. Jian. 2001. Continuous Turbidity Monitoring and Regression Analysis to Estimate Total Suspended Solids and Fecal Coliform Bacteria Loads in Real Time, III-94-III101. Edited by US Geological Survey USGS. US Geological Survey USGS.

Chuan, O. M., and K. Yunus. 2019. "Sediment and Organisms as Marker for Metal Pollution." In Monitoring of Marine Pollution, edited by H. B. Fouzia, 1-19. London, UK: IntechOpen.

Cohen, J., and J. C. M. Nee. 1987. "A Comparison of Two Noncentral F Approximations, with Applications to Power Analysis in Set Correlation." Multivariate Behavioral Research 22 (4): 483-490. doi:10.1207/s15327906mbr2204_6.

Cooper, C. M. 1993. "Biological Effects of Agriculturally Derived Surface Water Pollutants on Aquatic Systems-a Review." Journal of Environmental Quality 22 (3): 402-408. doi:10.2134/ jeq1993.00472425002200030003x.

Debret, M., D. Sebag, M. Desmet, W. Balsam, Y. Copard, B. Mourier, A.-S. Susperrigui, F. Arnaud, I. Bentaleb, and E. Chapron. 2011. "Spectrocolorimetric Interpretation of Sedimentary Dynamics: The New "Q7/4 Diagram"." Earth-Science Reviews 109 (1-2): 1-19. doi:10.1016/j.earscirev.2011.07.002.

Dekker, A. G., Ž. Zamurović-Nenad, H. J. Hoogenboom, and S. W. M. Peters. 1996. "Remote Sensing, Ecological Water Quality Modelling and in Situ Measurements: A Case Study in Shallow Lakes." Hydrological Sciences Journal 41 (4): 531-547. doi:10.1080/02626669609491524.

Dietrich, J. T. 2017. "Bathymetric Structure-from-motion: Extracting Shallow Stream Bathymetry from Multi-view Stereo Photogrammetry." Earth Surface Processes Landforms 42 (2): 355-364. doi:10.1002/esp.4060.

Din, S. E., Y. Z. Essam, and A. Suliman. 2017. "Mapping Concentrations of Surface Water Quality Parameters Using a Novel Remote Sensing and Artificial Intelligence Framework." International Journal of Remote Sensing 38 (4): 1023-1042. doi:10.1080/01431161.2016.1275056.

DJI. 2019. “DJI Phantom 4 Specs." https://www.dji.com/phantom-4/info\#downloads

Duda, A. M. 1993. "Addressing Nonpoint Sources of Water Pollution Must Become an International Priority." Water Science Technology 28 (3-5): 1-11. doi:10.2166/wst.1993.0398.

Ehmann, K., C. Kelleher, and L. E. Condon. 2019. "Monitoring Turbidity from Above: Deploying Small Unoccupied Aerial Vehicles to Image In-stream Turbidity." Hydrological Processes 33 (6): 1013-1021. doi:10.1002/hyp.13372.

Fitch, K., C. Kelleher, S. Caldwell, and I. Joyce. 2018. "Airborne Thermal Infrared Videography of Stream Temperature Anomalies from a Small Unoccupied Aerial System." Hydrological Processes 32 (16): 2616-2619. doi:10.1002/hyp.13218.

Friberg, N., N. V. Angelopoulos, A. D. Buijse, I. G. Cowx, J. Kail, T. F. Moe, H. Moir, M. T. O'Hare, P. F. M. Verdonschot, and C. Wolter. 2016. "Effective River Restoration in the 21st Century: From Trial and Error to Novel Evidence-based Approaches." In Advances in Ecological Research, 535-611. Vol. 55. Elsevier.

Gauci, A. A., C. J. Brodbeck, A. M. Poncet, and T. Knappenberger. 2018. "Assessing the Geospatial Accuracy of Aerial Imagery Collected with Various UAS Platforms." American Society of Agricultural and Biological Engineers 61: 1823-1829.

Gee, G., and J. Bauder. 1986. "Particle-size Analysis 1." In Methods of Soil Analysis: Part 1-Physical Mineralogical Methods. 2nd ed. Madison, Wl: The American Society of Agronomy and Academic Press.

Gippel, C. J. 1989. The Use of Turbidity Instruments to Measure Stream Water Suspended Sediment Concentration. Sydney, Australia: Hydrobiologia: Dept. of Geography and Oceanography, University College, the University of New South Wales, Australian Defence Force Academy.

Gregory, J. 1985. "Turbidity Fluctuations in Flowing Suspensions." Journal of Colloid Interface Science 105 (2): 357-371. doi:10.1016/0021-9797(85)90309-1.

Halfman, J., and C. Scholz. 1993. "Suspended Sediments in Lake Malawi, Africa: A Reconnaissance Study." Journal of Great Lakes Research 19 (3): 499-511. doi:10.1016/S0380-1330(93)71236-8.

Hicks, B. J., G. A. Stichbury, L. K. Brabyn, M. G. Allan, and S. Ashraf. 2013. “Hindcasting Water Clarity from Landsat Satellite Images of Unmonitored Shallow Lakes in the Waikato Region, New Zealand." Environmental Monitoring Assessment 185 (9): 7245-7261. doi:10.1007/s10661-0133098-2. 
Hilldale, R. C., and D. Raff. 2008. "Assessing the Ability of Airborne LiDAR to Map River Bathymetry." Earth Surface Processes Landforms 33 (5): 773-783. doi:10.1002/esp.1575.

Homer, C. G., J. A. Fry, and C. A. Barnes. 2012. "The National Land Cover Database." Fact Sheet. Reston, VA.

Iqbal, F., A. Lucieer, and K. Barry. 2018. "Simplified Radiometric Calibration for UAS-mounted Multispectral Sensor." European Journal of Remote Sensing 51 (1): 301-313. doi:10.1080/ 22797254.2018.1432293.

Kaplan, L. A., T. L. Bott, J. K. Jackson, J. D. Newbold, and B. W. Sweeney. 2008. "Protecting Headwaters: The Scientific Basis for Safeguarding Stream and River Ecosystems." In A Research Synthesis from the Stroud ${ }^{\mathrm{TM}}$ Water Research Center, edited by Matt Freeman, 1-18. Avondale, PA: Stround Water Research Centre.

Keeley, M., A. Koburger, D. P. Dolowitz, D. Medearis, D. Nickel, and W. Shuster. 2013. "Perspectives on the Use of Green Infrastructure for Stormwater Management in Cleveland and Milwaukee." Environmental Management 51 (6): 1093-1108. doi:10.1007/s00267-013-0032-x.

Klemas, V. V. 2015. "Coastal and Environmental Remote Sensing from Unmanned Aerial Vehicles: An Overview." Journal of Coastal Research 31 (5): 1260-1267. doi:10.2112/JCOASTRES-D-1500005.1.

Larson, M. D., A. S. Milas, R. K. Vincent, and J. E. Evans. 2018. "Multi-depth Suspended Sediment Estimation Using High-resolution Remote-sensing UAV in Maumee River, Ohio." International Journal of Remote Sensing 39 (15-16): 5472-5489. doi:10.1080/01431161.2018.1465616.

Lechner, A. M., A. Fletcher, K. Johansen, and P. Erskine. 2012. “Characterising Upland Swamps Using Object-based Classification Methods and Hyper-spatial Resolution Imagery Derived from an Unmanned Aerial Vehicle." Paper presented at the Proceedings of the XXII ISPRS Congress Annals of the Photogrammetry, Remote Sensing and Spatial Information Sciences, Melbourne, Australia.

Lega, M., J. Kosmatka, C. Ferrara, F. Russo, R. M. A. Napoli, and G. Persechino. 2012. “Using Advanced Aerial Platforms and Infrared Thermography to Track Environmental Contamination." Environmental Forensics 13 (4): 332-338. doi:10.1080/15275922.2012.729002.

Lega, M., and R. M. A. Napoli. 2010. "Aerial Infrared Thermography in the Surface Waters Contamination Monitoring." Desalination Water Treatment 23 (1-3): 141-151. doi:10.5004/ dwt.2010.1988.

Legleiter, C. 2012. "Remote Measurement of River Morphology via Fusion of LiDAR Topography and Spectrally Based Bathymetry." Earth Surface Processes Landforms 37 (5): 499-518. doi:10.1002/ esp.2262.

Léopold, E. N., M. C. Jung, O. Auguste, N. Ngatcha, E. Georges, and M. Lape. 2008. “Metals Pollution in Freshly Deposited Sediments from River Mingoa, Main Tributary to the Municipal Lake of Yaounde, Cameroon." Geosciences Journal 12 (4): 337-347. doi:10.1007/s12303-008-0034-5.

Leopold, L. B., M. Gordon Wolman, and J. P. Miller. 2012. Fluvial Processes in Geomorphology. Mineola, NY: Courier Corporation.

Leyland, J., C. R. Hackney, S. E. Darby, D. R. Parsons, J. L. Best, A. P. Nicholas, R. Aalto, and D. Lague. 2017. "Extreme Flood-driven Fluvial Bank Erosion and Sediment Loads: Direct Process Measurements Using Integrated Mobile Laser Scanning (MLS) and Hydro-acoustic Techniques." Earth Surface Processes Landforms 42 (2): 334-346. doi:10.1002/esp.4078.

Liu, Y., M. A. Islam, and J. Gao. 2003. "Quantification of Shallow Water Quality Parameters by Means of Remote Sensing." Progress in Physical Geography 27 (1): 24-43. doi:10.1191/0309133303pp357ra.

Lodhi, M. A., D. C. Rundquist, L. Han, and M. S. Kuzila. 1998. "Estimation of Suspended Sediment Concentration in Water Using Integrated Surface Reflectance." Geocarto International 13 (2): 11-15. doi:10.1080/10106049809354637.

Manfreda, S., M. McCabe, P. Miller, R. Lucas, V. P. Madrigal, G. Mallinis, E. B. Dor, D. Helman, L. Estes, and G. Ciraolo. 2018. "On the Use of Unmanned Aerial Systems for Environmental Monitoring." Remote Sensing 10 (4): 641. doi:10.3390/rs10040641.

McDonald, W. 2019. "Drones in Urban Stormwater Management: A Review and Future Perspectives." Urban Water Journal 16 (7): 505-518. doi:10.1080/1573062X.2019.1687745. 
McDowell, L. L., and K. C. McGregor. 1984. "Plant Nutrient Losses in Runoff from Conservation Tillage Corn." Soil Tillage Research 4 (1): 79-91. doi:10.1016/0167-1987(84)90018-7.

Menken, K. D., P. L. Brezonik, and M. E. Bauer. 2006. "Influence of Chlorophyll and Colored Dissolved Organic Matter (CDOM) on Lake Reflectance Spectra: Implications for Measuring Lake Properties by Remote Sensing." Lake Reservoir Management 22 (3): 179-190. doi:10.1080/07438140609353895.

Meyer, J. L., L. A. Kaplan, J. D. Newbold, D. L. Strayer, C. J. Woltemade, J. D. Zelder, R. Beilfuss, Q. Carpenter, R. Semlitsch, and M. C. Watzin. 2003. Where Rivers are Born: The Scientific Imperative for Defending Small Streams and Wetlands. Washington, DC: American Rivers and the Sierra Club.

Michalak, A. M., E. J. Anderson, D. Beletsky, S. Boland, N. S. Bosch, T. B. Bridgeman, J. D. Chaffin, K. Cho, R. Confesor, and D. Irem. 2013. "Record-setting Algal Bloom in Lake Erie Caused by Agricultural and Meteorological Trends Consistent with Expected Future Conditions." Proceedings of the National Academy of Sciences 110 (16): 6448-6452. doi:10.1073/pnas.1216006110.

Milas, S., J. Anita, J. Sousa, T. A. Warner, A. C. Teodoro, E. Peres, J. A. Gonçalves, et al. 2018. "Unmanned Aerial Systems (UAS) for Environmental Applications Special Issue Preface." International Journal of Remote Sensing 39: 4845-4851.

Minshall, G. W. 1988. "Stream Ecosystem Theory: A Global Perspective." Journal of the North American Benthological Society 7 (4): 263-288. doi:10.2307/1467294.

Mironga, J. M. 2004. "Geographic Information systems(GIS) and Remote Sensing in the Management of Shallow Tropical Lakes." Applied Ecology Environmental Research 2 (1): 83-103. doi:10.15666/ aeer/02083103.

Mitsch, W. J., and B. C. Reeder. 1992. "Nutrient and Hydrologic Budgets of a Great Lakes Coastal Freshwater Wetland during a Drought Year." Wetlands Ecology Management 1 (4): 211-222. doi:10.1007/BF00244926.

Nowak, M. M., K. Dziób, and P. Bogawski. 2019. “Unmanned Aerial Vehicles (Uavs) in Environmental Biology: A Review." European Journal of Ecology 4 (2): 56-74. doi:10.2478/eje-2018-0012.

Packman, J., K. Comings, and D. Booth. 1999. “Using Turbidity to Determine Total Suspended Solids in Urbanizing Streams in the Puget Lowlands." In Canadian Water Resources Association annual meeting, 158-165. Vancouver, BC.

Paul, J. F., R. Kasprzyk, and W. Lick. 1982. "Turbidity in the Western Basin of Lake Erie." Journal of Geophysical Research: Oceans 87 (C8): 5779-5784. doi:10.1029/JC087iC08p05779.

Perez, M. A., W. C. Zech, W. N. Donald, and X. Fang. 2014. "Methodology for Evaluating Inlet Protection Practices Using Large-scale Testing Techniques." Journal of Hydrologic Engineering 20 (4): 04014049. doi:10.1061/(ASCE)HE.1943-5584.0001019.

Perez, M. A., W. C. Zech, W. N. Donald, and X. Fang. 2016. "Design Methodology for the Selection of Temporary Erosion and Sediment Control Practices Based on Regional Hydrological Conditions." Journal of Hydrologic Engineering 21 (4): 05016001. doi:10.1061/(ASCE)HE.1943-5584.0001328.

Pimentel, D., and N. Kounang. 1998. "Ecology of Soil Erosion in Ecosystems." Ecosystems 1 (5): 416-426. doi:10.1007/s100219900035.

Poesen, J. W., J. Boardman, B. Wilcox, and C. Valentin. 1996. "Water Erosion Monitoring and Experimentation for Global Change Studies." Journal of Soil Water Conservation 51 (5): 386-390.

Poncet, A. M., T. Knappenberger, C. Brodbeck, M. Fogle, J. N. Shaw, and B. V. Ortiz. 2019. "Multispectral UAS Data Accuracy for Different Radiometric Calibration Methods." Remote Sensing 11 (16): 1917. doi:10.3390/rs11161917.

Potter, K. N., H. A. Torbert, and J. E. Morrison Jr. 1995. "Tillage and Residue Effects on Infiltration and Sediment Losses on Vertisols." Transactions of the ASAE 38 (5): 1413-1419. doi:10.13031/ 2013.27965.

Rabení, C. F., and G. W. Minshall. 1977. Factors Affecting Microdistribution of Stream Benthic Insects, Oikos:33-43. Copenhagen, Denmark: Wiley.

Rabení, C. F., K. E. Doisy, and L. D. Zweig. 2005. "Stream Invertebrate Community Functional Responses to Deposited Sediment." Aquatic Sciences 67 (4): 395-402. doi:10.1007/s00027-0050793-2. 
Rabení, C. F., and R. B. Jacobson. 1999. "Warmwater Streams." Inland Fisheries Management in North America, edited by W. A. Hubert and M. C. Quist, 505-528. Herndon, VA: American Fisheries Society.

Ries, K. G., J. K. Newson, M. J. Smith, J. D. Guthrie, P. A. Steeves, T. L. Haluska, K. R. Kolb, R. F. Thompson, R. D. Santoro, and H. W. Vraga. 2017. "StreamStats, Version 4." In Fact Sheet. Reston, VA.

Rügner, H., M. Schwientek, M. Egner, and P. Grathwohl. 2014. "Monitoring of Event-based Mobilization of Hydrophobic Pollutants in Rivers: Calibration of Turbidity as a Proxy for Particle Facilitated Transport in Field and Laboratory." Science of the Total Environment 490: 191-198. doi:10.1016/j.scitotenv.2014.04.110.

SAS, Institute Inc. 1982. "SAS Institute Inc. SAS User's Guide: Basics." In, 923. Cary, NC.

SAS, Institute Inc. 1985. "SAS Institute Inc. SAS User's Guide: Statistics." In, 956. Cary, NC.

Schaeffer, B. A., K. G. Schaeffer, R. S. Darryl Keith, R. C. Lunetta, and R. W. Gould. 2013. "Barriers to Adopting Satellite Remote Sensing for Water Quality Management." International Journal of Remote Sensing 34 (21): 7534-7544. doi:10.1080/01431161.2013.823524.

Schindler, R. J., and A. Robert. 2004. "Suspended Sediment Concentration and the Ripple-dune Transition." Hydrological Processes 18 (17): 3215-3227. doi:10.1002/hyp.1505.

Sequoia, P. 2019. Datasheet: The Multi-Band Sensor Designed for Agriculture. edited by Parrot Drones S.A.S.. Paris, France: Parrot Drones S.A.S.

Steeves, P., and D. Nebert. 1994. "1:250,000-scale Hydrologic Units of the United States." Reston, Virginia.

Su, T.-C. 2017. "A Study of A Matching Pixel by Pixel (MPP) Algorithm to Establish an Empirical Model of Water Quality Mapping, as Based on Unmanned Aerial Vehicle (UAV) Images." International Journal of Applied Earth Observation Geoinformation 58: 213-224. doi:10.1016/j.jag.2017.02.011.

Sweeney, B. W., T. L. Bott, J. K. Jackson, L. A. Kaplan, J. Denis Newbold, L. J. Standley, W. Cully Hession, and R. J. Horwitz. 2004. "Riparian Deforestation, Stream Narrowing, and Loss of Stream Ecosystem Services." Proceedings of the National Academy of Sciences 101 (39): 14132-14137. doi:10.1073/ pnas.0405895101.

Tomsett, C., and J. Leyland. 2019. "Remote Sensing of River Corridors: A Review of Current Trends and Future Directions." River Research Applications. doi:10.1002/rra.3479.

Torbert, H. A., K. N. Potter, and J. E. Morrison. 1996. "Management Effects on Nitrogen and Phosphorus Losses in Runoff on Expansive Clay Soils." Transactions of the ASAE 39 (1): 161-166. doi:10.13031/2013.27494.

Tyler, A. N., E. Svab, T. Preston, M. Présing, and W. A. Kovács. 2006. “Remote Sensing of the Water Quality of Shallow Lakes: A Mixture Modelling Approach to Quantifying Phytoplankton in Water Characterized by High-suspended Sediment." International Journal of Remote Sensing 27 (8): 1521-1537. doi:10.1080/01431160500419311.

Umar, M., B. L. Rhoads, and J. A. Greenberg. 2018. "Use of Multispectral Satellite Remote Sensing to Assess Mixing of Suspended Sediment Downstream of Large River Confluences." Journal of Hydrology 556: 325-338. doi:10.1016/j.jhydrol.2017.11.026.

USEPA, United States Environmental Protection Agency. 1971. "Standard operating procedure for the analysis of residue, nonfilterable (suspended solids), water, method 160.2." Washington D.C.

USEPA, United States Environmental Protection Agency. 1993. Method 180.1: Determination of Turbidity by Nephelometry, edited by. Washington D.C: United States Environmental Protection Agency.

USEPA, United States Environmental Protection Agency. 2015. WATERS Geospatial Data. Washington DC: United States Environmental Protection Agency.

Vogt, M. C., and M. E. Vogt. 2016. "Near-remote Sensing of Water Turbidity Using Small Unmanned Aircraft Systems." Environmental Practice 18 (1): 18-31. doi:10.1017/S1466046615000459.

Walker, W. J., R. P. McNutt, and M. CarolAnn K. 1999. "The Potential Contribution of Urban Runoff to Surface Sediments of the Passaic River: Sources and Chemical Characteristics." Chemosphere 38 (2): 363-377. doi:10.1016/S0045-6535(98)00186-6.

Wohl, E., B. P. Bledsoe, R. B. Jacobson, N. LeRoy Poff, S. L. Rathburn, D. M. Walters, and A. C. Wilcox. 2015. "The Natural Sediment Regime in Rivers: Broadening the Foundation for Ecosystem Management." BioScience 65 (4): 358-371. doi:10.1093/biosci/biv002. 